\title{
ОТНОШЕНИЕ К РОДИТЕЛЬСКОЙ СЕМЬЕ В ПОДРОСТКОВОМ ВОЗРАСТЕ И ОСОБЕННОСТИ ЛИЧНОСТНОГО И МОРАЛЬНО-НРАВСТВЕННОГО РАЗВИТИЯ
}

\author{
Горлова Е.Л. (ФГБОУ ВО «Российский государственный \\ гуманитарный университет», \\ ГАОУ ВО “Московский городской педагогический университет», \\ Лаборатория проектирования культурно-исторических \\ моделей образования, Москва, Россия) \\ el_gorlova@mail.ru

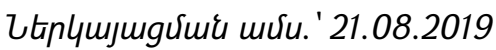

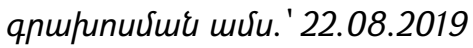

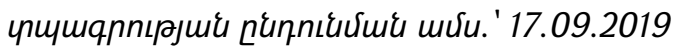

Взросление современных подростков осложнено транзитивностью современного общества. Традиции и ценностные опоры, которые раньше давали семьи и общество размыты. Развитие в подростничестве можно сравнить с тектоническими процессами, которые фриксируются исследователями, но предсказать их последствия достаточно сложно. Вопрос, который стоит перед нами, выяснить, каким образом реализуются семейные ценности в личностных выборах подростков. Цель: выявить представления современных подростков о семье, сравнить с результатами оценки личностного и морально-нравственного развития. Гипотеза: содержание представлений о семье связано с личностным и морально-нравственным развитием подростков. Рассмотрены результаты по каждому опроснику отдельно и проведён корреляционный анализ результатов. Ценность семьи подростков связана с качеством семейного окружения, а отношение к труду соотносится с качеством образовательной и культурной среды.

Ключевые слова: подростки, личностное развитие, ченности, семейные отношения.

Введение. Феноменология подросткового возраста исследуется как в работах отечественных авторов, так и зарубежных в связи с современным социокультурным контекстом [1; 3; 4; 6; 8]. К примеру, в исследовании J.L. Finn, L.M. Nybell, J.J. Shook рассматриваются специфические черты современного взросления детей и подростков: маргинализация, медикализация, маркетизация, милитаризация и мобилизация [8]. А в работе Л.Ф. Обуховой и И.А. Корепановой приведены примеры из эссе о современном ребёнке, написанные респондентами в России, представителями разных социальных слоев и возраста [3]. Авторы делают вывод, что выделенные зарубежными авторами черты взросления в эпоху глобализации относятся и к взрослению подростков в России. Кратко опишем эти черты, 
которые на наш взгляд являются серьёзным противовесом в развитии гуманистических ценностей подрастающего человека.

Маргинализация - результат неравного доступа детей и подростков к использованию образовательных, культурных ресурсов (разница уровня благосостояния семей, увеличение количества платных услуг, снижение инвестирования системы государственных учреждений и организаций, ориентированных на развитие детей и молодёжи). Маркетизация мира детства означает, что дети выступают объектом экономической деятельности. Образы детей используются в продвижении тех или иных товаров и услуг. Медикализация связана с маркетингом, когда проблемы развития и поведения детей представлены через медицинские термины и диагнозы, рост фрармакологических способов контроля за агрессией, гиперактивностью детей. Повышение родительской тревоги за статус психического здоровья детей, использование терапии вместо естественных для развития ребёнка культурных инструментов. Милитаризация связана с тем, что фоном для детства являются террористические атаки и антитеррористические операции, военные действия в различных точках мира. Вовлечение детей и подростков, проживающих в горячих точках в военные действия. Очевидно влияния дискурса милитаризации на мир компьютерных игр, на выбор подростками одежды, увлечений. Мобилизация состоит в осознании подростками своего влияния на общественные процессы, их активность в борьбе за социальные и политические перемены, объединения в нефрормальные организации, противостоящие властным дискурсам.

Происходящие социокультурные трансформации можно сравнить с тектоническими сдвигами, результат которых предсказать невозможно. Одна из актуальных проблем психологии подросткового возраста, это вопрос о содержании развития и его результатах в данной социокультурной ситуации $[3 ; 4 ; 6]$.

Цель исследования. В нашем исследовании мы поставили целью рассмотреть личностное и морально-нравственное развитие подростков в связи с их отношением к родительской семье [1].

Сохраняет ли своё влияние семья на становление ценностей подростков? Гипотеза нашего эмпирического исследования состояла в том, что содержание оценок подростками своего семейного окружения будет связано со спецификой ценностей современного подростка.

Выборка. В исследовании принимали участие учащиеся подмосковного колледжа в возрасте от 16 до 19 лет (средний возраст 17,5 лет, ст. отклонение 0,8) получающие среднее специальное образование гуманитарного и технического профиля. Всего приняли участие 205 человек, студенты первого и второго курсов. Исследование проводилось анонимно, 53,4\% участников указали свой пол, 46,1\% не указали. Среди респондентов, указавших свой пол, 36,3 \% - юноши, 17,6\% девушки. Состав семей участников: 45\% - нуклеарные семьи с одним или двумя, тремя детьми, 3\% сироты, 26\% - неполная семья (с мамой, либо мамой и сиблингом, 
либо мамой и бабушкой) и $26 \%$ - расширенная семья с включением представителей старшего поколения, иногда с проживанием братьев и сестер родителей.

Методы исследования. 1) Шкала семейного окружения (Family Environmental Scale, FES, Rudolf H. \& Bernice S. Moos), русскоязычная адаптация С.Ю. Куприянова (ШСО) (опросили 137 человек) [2]. ШСО включает 10 шкал, каждая из которых представлена девятью пунктами, имеющими отношение к характеристике семейного окружения. Три шкалы на изучение отношений между членами семьи (сплочённость, экспрессивность, конфликтность). Пять шкал измеряют выраженность ценностей личностного роста в семье (независимость, ориентация на достижения членов семьи, интеллектуально-культурная ориентация, ориентация на активный отдых, морально-нравственные аспекты). Две шкалы оценивают качество управления семейной системой (организация и контроль).

2) Опросник личностного роста (Степанов П.В., Григорьев Д.В., Кулешова И.В.) позволяет дать характеристику ценностных отношений подростка к миру, к людям и к самому себе (всего 13 шкал). Всего заполнили анкеты ОРЛ 166 участников [5]. Обе методики заполнили 99 человек.

Результаты и их обсуждение. В сборе результатов и их обработке участвовали магистранты первого курса РГГУ, обучающиеся по образовательной программе «Семейная психопедагогика».

На Рис. 1 представлены результаты оценки подростками характеристик своего семейного окружения по методике «Шкала семейного окружения».

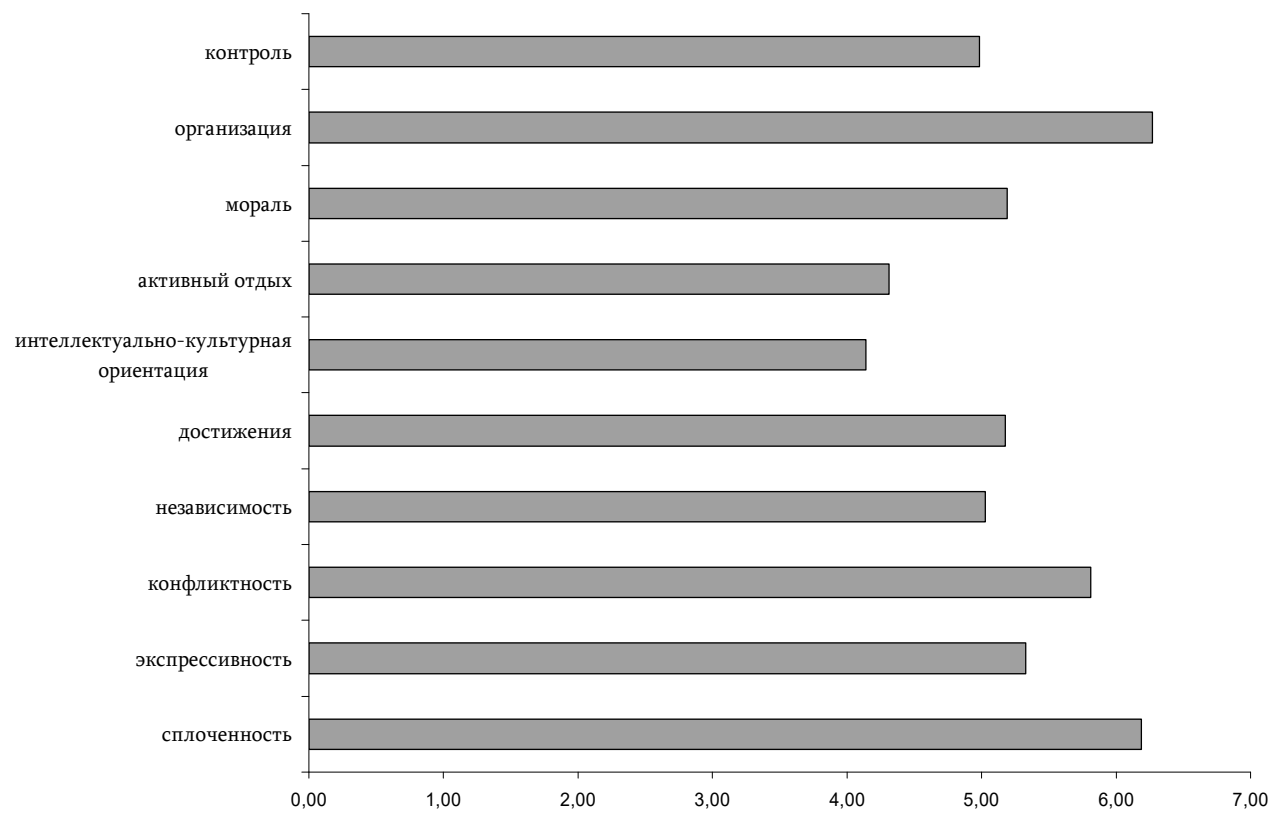

Puc. 1. Шкала семейного окружения: средние значения по каждой шкале ( $N=137)$ 
Средний показатель по каждой шкале оценки семейного окружения варьируется от 3 до 7 баллов. На нашей выборке все шкалы получили оценку в среднем регистре. Вместе с тем, отметим, что на границе с высоким уровнем находятся значения по шкалам «организация» (6,3), «сплочённость» $(6,2)$, «конфликтность» $(5,8)$, а на границе с низкими значениями, оценка по шкале «интеллектуально-культурная ориентация» $(4,1)$. Такое сочетание показателей семейного окружения характеризует семью студентов колледжа как сплочённую, с высокими требованиям к порядку, и соблюдению установленных правил и неконфрликтными отношениями членов семьи. В опроснике ШСО высокие показатели по шкале «конфликтность» интерпретируется как низкий уровень конфликтогенности семейных отношений. Близкие к нижней границе значения по шкале «интеллектуально-культурная ориентация» говорит о сниженной активности членов семьи в социальной, интеллектуальной, культурной и политической сферах деятельности. Возможно, поступление подростков в колледж (а не выбор полного среднего образования и вуза) связан именно со сниженным интеллектуальнокультурным потенциалом семей.

На рисунке 2 проиллюстрированы результаты опросника личностного роста. Разработчики методики основывались на той позиции, что именно отношение человека к окружающему миру, к другим людям, к самому себе являются результатами воспитания и морально-нравственного развития. Авторы предлагают рассматривать сумму баллов от 15 до 28 как устойчиво-позитивное отношение к выделенной сфере, а в границах от -14 до -28 - устойчиво-негативное. Остальные значения со знаком «плюс» определяются как ситуативно-позитивное отношение, а со знаком «минус» - ситуативно-негативное отношение. Выбор подростков в пользу гуманистических ценностей в психологии соотносится с личностным ростом и здоровьем. Как видим на диаграмме, 12 сфер находятся в регистре ситуативнопозитивного отношения. При этом две сореры находятся на границе устойчивопозитивного отношения - это шкалы "отношение к труду" и «отношение к семье». Это означает, что престижная работа вызывает уважение подростков, и что подростки обследуемой нами группы (студенты колледжа) ориентированы на поиск работы в будущем. Семья воспринимается ими, как естественный факт предназначения человека. При этом подростки склонны считать, что семья, которую они создадут в будущем, будет отличаться от родительской в лучшую сторону. 


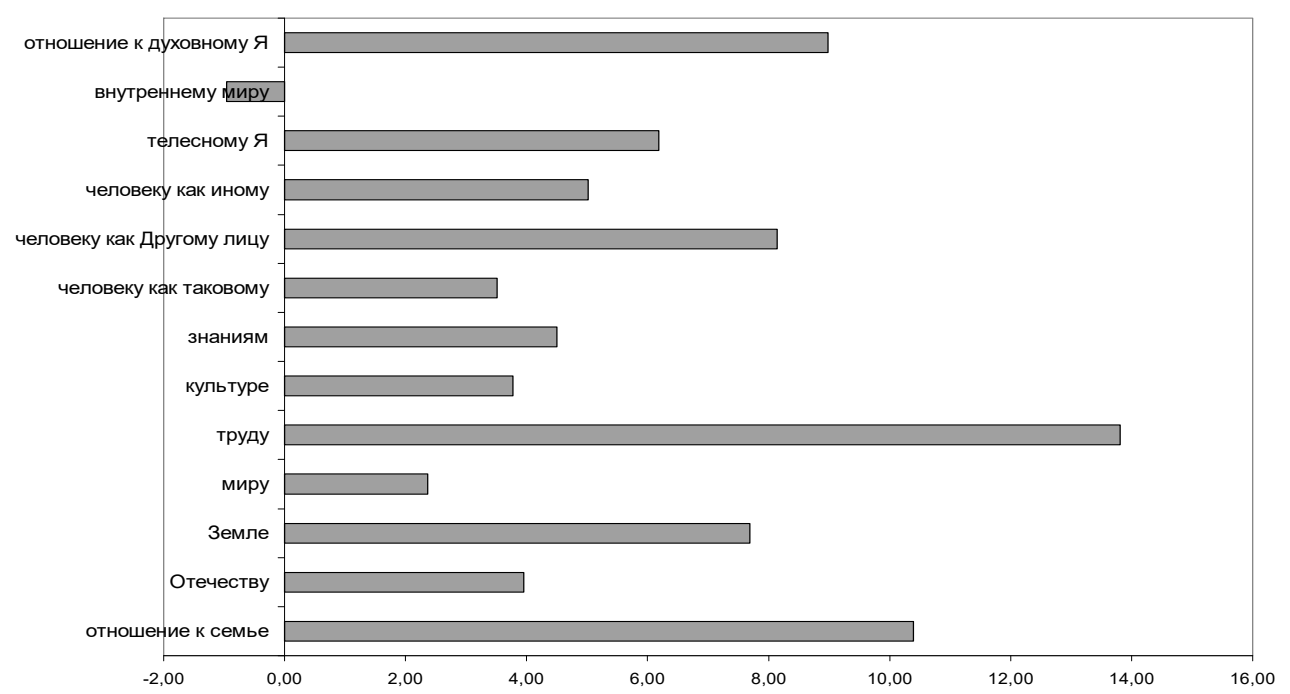

Puc. 2. Опросник личностного роста: средние значения по каждой шкале ( $N=166)$

Одна сфера получила отрицательную оценку - это ситуативно-негативное отношение к внутреннему миру, что на наш взгляд свидетельствует о кризисе идентичности подростков, обучающихся в колледже. Отметим, что этап подростничества традиционно соотносится с кризисом идентичности (Э. Эриксон, Дж. Марсиа) [7; 9]. Сегодня, в транзитивном мире подросткам сложнее преодолевать этот кризис. Подросток принимает себя таким, какой он есть, лишь в отдельные моменты своей повседневной жизни.

Сравним полученные результаты по двум методикам с помощью корреляционного анализа (коэффрициент корреляции Пирсона, SPSS 23.0). В связи с тем, что корреляционная матрица (10 шкал методики «Шкала семейного окружения» и 13 шкал «Опросника личностного роста») содержит более 100 значимых связей. Мы отметим только те, связи, которые имеют более высокий уровень значимости и отвечают на поставленные в нашем исследовании вопросы о связях семейного окружения и ценностей подростков. Рассмотрим, с какими характеристиками семейного окружения связаны отношение подростков к семье и к труду - важнейшие сферы самореализации взрослых людей, которые набрали у подростков максимальные оценки из всех шкал опросника личностного роста.

Положительно коррелируют с отношением к семье (в порядке снижения значимости связи) такие шкалы ШСО, как «независимость в семье» $(p \leq 0,003)$, «семейная организация» $(p \leq 0,006)$, «сплочённость членов семьи» $(0,026)$, «конфрликтность» $(p \leq 0,037)$. Таким образом, чем более выражено позитивное отношение в семье, тем выше показатели по шкалам, определяющем положительный микроклимат в семье. И соответственно, чем выше оценка подростка его 
собственной независимости в семье, чем выше показатели сплочённости членов семьи, организации и неконфликтности, тем устойчивее позитивное отношение подростка к семейным ценностям. Подтвердился и ожидаемый нами фракт, что внутри каждого опросника шкалы имеют достаточно много перекрещивающихся связей, что свидетельствует в первую очередь о хорошем качестве выбранных исследовательских инструментов. К примеру, интересующая нас шкала «отношение к семье» положительно коррелирует с другими шкалами этого же опросника (ОЛР), например, «отношение к Отечеству" ( $\leq \leq 0,0001)$, «отношение к культуре» $(p \leq 0,001)$, «отношение к человеку, как Другому» $(p \leq 0,001)$, «отношение к труду» $(p \leq 0,006)$ а также отношение к своему телесному $(p \leq 0,028)$ и внутреннему Я $(\mathrm{p} \leq 0,005)$.

Таким образом, можно сделать первый вывод о том, что в эпоху сдвига ценностей в сторону индивидуализации, семейное окружение сохраняет свой вес в укреплении, в первую очередь, семейных и общечеловеческих ценностей (Отечества, человека, культуры, личности). Интересный результат мы получили при анализе связей шкалы «отношение к труду» с качеством семейного окружения в подростковом возрасте: не выявлено ни одной корреляционной связи с ШСО, но выявили высокий уровень значимости связей внутри опросника личностного роста. Наиболее тесная связь «отношения подростка к труду» обнаружена с такими характеристиками, как “отношение к человеку, как Другому лицу» ( $\leq \leq 0,0001)$, «отношение к знаниями» ( $p \leq 0,0001)$, «отношение к культуре» $(p \leq 0,0001)$, к «духовному Я» $(p \leq 0,0001)$. Это результат показывает, что общественная направленность подростка фрормируется в более широком социальном контексте, именно образовательная среда и её характеристики соотносятся с выбором подростка, в пользу построения своей будущей карьеры и ценности труда.

Ответим также на вопрос о связях шкалы «отношение к внутреннему миру» ОлР с качеством семейного окружения. Наиболее тесная связь данной характеристики обнаружена с ориентацией семьи на активный отдых, т.е., чем выше в семье степень участия в различных видах активного отдыха и спорта, тем выше оценивается внутренний мир $(\mathrm{p} \leq 0,0001)$. Также высокая значимость связей с теми же шкалами ШСО, как и ценности семьи. Таким образом, мы получили подтверждение нашей общей гипотезы о связи качества семейного окружения с ценностным отношением к семье и самому себе. При этом отношение к труду коррелирует не со шкалами семейного окружения, а с качеством образовательной среды. В нашем исследовании имеются другие интересные данные о современных подростках, в частности, особенности развития их рефрлексии и понятийного мышления, отношение к прошлому, настоящему и будущему. Одно из серьёзных ограничений для нашего исследования оказалось добровольное и анонимное участие в исследовании подростков. Мы получили низкий процент заполнения всех материалов. Как видим, из 205 участников оба опросника заполнили только 
половина студентов. Также отметим, что сниженные показатели развития рефлексии являются значительным барьером в использовании опросников в групповом формате, так, например, не все респонденты понимают, как отвечать на вопросы с использованием отрицания. Считаем перспективным разработку такого инструментария, который соотносится с особенностями мышления и речевых возможностей современных подростков.

Выводы. В эпоху глобализации на взросление подростков влияют такие черты социокультурного контекста, как маргинализация, медикализация, маркетизация, милитаризация и мобилизация. Для выбора подростками семейных ценностей важны следующие характеристики семейного окружения: «независимость», т.е. поощрение в семье самостоятельности в обдумывании проблем и принятии решений; «сплочённость членов семьи», т.е. выраженность в семейном окружении чувства принадлежности к семье, высокой степени заботы членов семьи друг о друге; «организованность», как степень важности для семьи структурирования семейной активности, финансового планирования, ясности и определённости семейных правил и обязанностей; «неконфликтность» семейного окружения подростков. Для выбора ценности труда и карьеры значимыми являются такие сопряжённые ценности подростков: «отношение к человеку, как Другому», «отношение к знаниями», «отношение к культуре», к «духовному Я».

Наше исследование показало, что при проведении анонимного исследования значительное число респондентов при групповом проведении исследования заполняет опросники формально, пропускает вопросы, не проявляют интереса к индивидуальным результатам. В нашем случае 50\% бланков были испорчены. Считаем, что сегодня требуется поиск новых инструментов и организационных условий для проведения более масштабных исследований содержания развития в подростковом возрасте.

\section{Литература}

1. Горлова Е.Л. Представления о семье у подростков разного психологического возраста// Культурно-историческая психология. 2018. Том 14. № 2. С. 24-32. doi:10.17759/chp.2018140203

2. Лидерс А.Г. Психологическое обследование семьи: учебное пособие-практикум для студ.фрак.психологии высш.уч.завед. М.: Издательский центр «Академия», 2007. 432 c.

3. Обухова Л.Ф., Корепанова И.А. Современный ребенок: шаги к пониманию. Психологическая наука и образование. 2010. № 10. С. 5-19.

4. Поливанова К.Н. Новое детство: вызов культурно-исторической теории?/ У истоков развития. Сборник научных статей / К.Н. Поливанова; Ред.: Л. Ф. Обухова, И. А. Котляр (Корепанова). М.: ГБОУ ВПО МГППУ, 2011. С. 128-134. 
5. Степанов П.В., Григорьев Д.В., Кулешова И.В. Диагностика и мониторинг процесса воспитания в школе / Под ред. Н.Л. Селивановой, В.М. Лизинского. М.: АПК и ПРО, 2003. 83 c.

6. Толстых Н.Н. Современное взросление//Консультативная психология и психотерапия. 2015. №4. С. 7-24.

7. Эриксон Э. Идентичность: юность и кризис. М.: Прогресс, 1996. 344 с.

8. Finn J.L., Nybell L.M., Shook J.J. The meaning and making of childhood in the era of globalization: Challenges for social work // Children and Youth Services Review, 2010 32. P. 246-254.

9. Marsia J. E. Identify in adolescence // Handbook of adolescent psychology/ Sd.by. h Adolson N.Y., 1980. P. 212-231.

\section{ATTITUDE TO THE PARENTAL FAMILY IN ADOLESCENCE AND THEIR PERSONAL AND MORAL DEVELOPMENT}

Gorlova E.L. (Russian State University for the Humanities, Moscow City University, Moscow, Russia)

The development of adolescents is complicated by the transitivity of modern society, destruction of family values and traditions collapse. Our question: how family values are realized in the personal choices of adolescents. Objective: study of the personal development and perceptions of adolescents about the family, comparing with the results of the evaluation of education, and moral development. Hypothesis: the content of ideas about the family is associated with the personal and moral development of adolescents. The attitude of adolescents to the family, the effectiveness of the process of education are investigate. All results are analyzed in detail separately and a correlation analysis of the results is carried out. Family values of adolescents are associated with the quality of the family environment, and attitude to work is correlated with the quality of the educational and cultural environment.

Keywords: adolescences, personal development, values, family relationships. 